\title{
Culture EFFECT ON REQUIREMENTS Elicitation Practice IN DEVEloping COUNTRIES
}

\author{
Ayman Sadig ${ }^{1}$ and Abd-El-Kader Sahraoui ${ }^{2}$ \\ ${ }^{1}$ Ahfad University for Women and SUST Khartoum Sudan \\ ${ }^{2}$ LAAS-CNRS, Université de Toulouse, CNRS, U2J, Toulouse, France
}

\begin{abstract}
Requirement elicitation is a very important step into developing any new application. This paper will examine the culture effect on requirement elicitation in developing countries.

This is a unique research that will look at requirement elicitation process in 10 different parts of the world including Arab word, India, China, Africa and South America. The focus is how the culture affects (RE) and makes every place has its own practice of RE. The data were collect through surveys and direct interviews. The results show astonishing culture effect on RE.

The conclusion is that culture effects deeply the technique gets chosen for requirement elicitation. If you are doing $R E$ in Thailand, it will be very different from RE in Arab world. For example in Thailand respect for leader is critical and any questioning of manager methods will create a problem while in Arab world decision tree is favourite RE technique because visual are liked much more than documents.
\end{abstract}

\section{KEYWORDS}

Culture impact, requirement elicitation

\section{INTRODUCTION.}

Gathering requirement is important step at any project. Requirement in Oxford Dictionary means 'A thing that is needed or wanted'. Weigers [33] argue that software requirement is understood different from requirement in the dictionary. The IEEE define requirement as a 1-condition or capability needed by a user to solve a problem or achieve an objective. 2. a condition or capability that must be met or possessed by a system or system component to satisfy a contract, standard, specification, or other formally imposed document 3. a documented representation of a condition or capability as in (1) or (2).

Every software project needs to know the desires of all stakeholders [1]. This process is called Requirement elicitation. Requirement elicitation can affect the entire software development activity if not properly executed. It is one of the common reasons for software project failure [2].

Requirement elicitation has been known in software engineer society since the 1960s. it is generally understood and accepted that requirements are elicited rather than just captured or collected. A developing country according to oxford dictionary is a poor agricultural country that is seeking to become more advanced economically and socially. 
Getting requirement elicitation is complex process. Requirement can't be gathered out of the social context[3]. Robertson and Robertson call it "trawling for requirements" [4] meaning that you are likely to get more requirements than expected but it is better than getting less. It comes after project initiation and before system design. It has many techniques like interview, questionnaire, work shop and prototype [5] and can happen with direct approach like interview or indirect like questionnaire [31].

The impact of this research will be a game changer in gathering requirement in developing countries as a good practice and tool will help a lot of companies get this vital stage right which will improve success rate of projects. Requirement Elicitation has attracted a lot of research but still this research could not find a single survey for culture effect in requirement elicitation in developing countries. This will be the first survey of culture effect of requirement elicitation in different countries around the world.

This paper will look first at what is meaning by culture then will address culture effect on requirement elicitation in many countries and regions in the world including Arab world, China, Brazil, Germany, Sudan, Thailand, Helsinki, Las Vegas and Hong Kong.

\section{What Does Culture Means?}

63 years ago, Kluckhohn argued 'culture is to society what memory is to individual' [9]. Hofstede explain culture as a 'set of shared assumptions that result in a common frame of reference by members of a society or more simply as mental software'. [6] Schein reckon culture is 'a set of structures, routines, rules, and norms that guide and constrain behavior' [7]. Lytle et al [8] put culture as beliefs and values that make sense of our behavior in the past and the future and if you take the behavior out of the culture context it will make no sense at all. Traindis [10] see a difference between individual culture such as North America and western Europe and collective culture of Asia, Africa and South America

So how can we measure value of culture, Hoststede [6] divide it the value of culture into two, values and practice. Value is everything a child learns before the age of 10 which stick in his mind and hard to change later, while practice is what is learnt later through social experience which is easier to modify.

Rokeach [11] has distinguish values into terminal which the end goal for human and instrumental which is the behavior to achieve the terminal goals. Rokeach [11] created a list of 36 values dividing them into terminal and instrumental. He divide terminal values into interpersonal values which concern other people and intrapersonal focus value which concern about the individual. As for instrumental values, it consists of moral and competency values.

Karahanna et al [12] upgrade Rokeach typology by dividing culture into 5 levels supranational, national, professional, organizational and group. Supranational is cross country boundary that exist in more than one country like ethnics, religion, regional and linguistic. Secondly National is collective behavior in one nation. Thirdly Professional the challenge between following industry culture or employee culture. Fourthly, organizational which are the social and politics that distinguish each organization. And finally group culture which is the difference in a group which is less than organisation. Tuure Tunnanen ET al [13] have mix Rekeach with Karahanna view in level of culture and came with following table. Tunnanen put the 36 values of Rokeach [11] and added extra values from Karahanna [12] like self respect, security, equality and freedom. 


\begin{tabular}{|c|c|c|}
\hline & Terminal & Instrumental \\
\hline $\begin{array}{l}\text { Interpersonal } \\
\text { focus }\end{array}$ & $\begin{array}{l}\text { SOCIAL VALUES: } \\
\text { A World of Peace } \\
\text { A World of Beauty } \\
\text { Equality } \\
\text { Family Security } \\
\text { National Security } \\
\text { Freedom } \\
\text { Social Recognition } \\
\text { True Friendship } \\
\text { Salvation }\end{array}$ & $\begin{array}{l}\text { MORAL VALUES: } \\
\text { Forgiving } \\
\text { Helpful } \\
\text { Honest } \\
\text { Obedient } \\
\text { Polite } \\
\text { Responsible } \\
\text { Loving }\end{array}$ \\
\hline $\begin{array}{l}\text { Intrapersonal } \\
\text { focus }\end{array}$ & $\begin{array}{l}\text { PERSONAL } \\
\text { VALUES: } \\
\text { A Comfortable Life } \\
\text { An Exciting Life } \\
\text { A Sense of } \\
\text { Accomplishment } \\
\text { Happiness } \\
\text { Pleasure } \\
\text { Inner Harmony } \\
\text { Mature Love }\end{array}$ & $\begin{array}{l}\text { COMPETENCY } \\
\text { VALUES: } \\
\text { Ambitious } \\
\text { Broad-minded }\end{array}$ \\
\hline
\end{tabular}

Figure 1. Tunnanen [13] show Value typology (based on Karahanna [12]; and Rokeach, [11])

\section{LITERATURE REVIEW}

\subsection{Introduction:}

This chapter gives a brief overview of the related work, first about the benchmark Requirement elicitation techniques in developed work. Then I will look at previous studies in developing world like Arab world, Africa and India, South America and China describing them, objective, limitation and further work needed to improve them. Finally I will summarize the literature review chapter

\subsection{Related work}

Requirement elicitation has improved a lot in the last 30 years. A lot of studies have been done in US, Europe and Japan. Requirement elicitation techniques in developed countries have been listed [26]. But there is still not a lot of research done in developing countries which has its unique social, economic and political circumstances. This study will cover important work done in developed countries then focus on requirement elicitation studies in developing countries

\subsubsection{Requirement elicitation in Arab World (Kuwait example) [21]}

There are 23 Arab country sharing similar culture, values, language, history and geographic location. There is not a lot of study's done to analyze RE in Arab world but a study in Kuwait show that the Arab culture influence heavily the perception of RE techniques, the companies in the survey know about 19 different techniques of RE and use many of them. The most used technique is interview but it is not valued highly. The companies like most Decision tree and prototyping. The least liked are UML, tree analysis, role playing K.J. method, flow chart and Ishikawa.

The study show that the culture play a big role in perception about RE, as for example although interview are cited as the most effective technique in developed world [14] and it is the most used in Kuwait but it is not regarded with great value. 
There are six main differences between western countries and Kuwait in the way it perceive RE techniques that are related to the Arab culture. First decision tree is the most value RE techniques unlike the western perception [14] because it is a graphical representation which bud well with Arab culture that like visual more than document and words [15] which make it easier to understand by stakeholders. A prototype is $3^{\text {rd }}$ highly valued RE techniques. A prototype is about developing a pilot system and shows it to stakeholders. Been $3^{\text {rd }}$ high challenge the result of western countries [16] but similar to study in Thailand market [17]. This also can be traced to culture reasons as Arabic culture score similar score to Thailand in Arab culture scores 68 on Hofstede uncertainty avoidance $(68,64)$, while the USA (a western culture) scored a 46 . Fourthly DFD is very popular in Kuwait as $4^{\text {th }}$ highly liked and secondly used which challenged the finding in western countries [14]. Fifthly there is a disliking for group techniques like JAD (ranked 8), focus group (ranked 9) and brain storming (ranked 11) which again in not consistent with outside of Arab world[18]. Lastly UML was the least liked RE techniques which contrast heavily with the developing countries where UML is regarded highly [19]. The study regards that for unfamiliarity with UML in Kuwait.

The study shows that Arab culture plays a crucial role in choosing the RE techniques. The main limitation is that it suggest all Arab countries are similar when there is big different in wealth, size, population, how many languages in the country and education level.

\begin{tabular}{|l|c|c|}
\hline RE technique & Cited & \% \\
\hline 1. Interviews & 79 & 91 \\
\hline 2. DFD & 65 & 75 \\
\hline 3. Brainstorming & 64 & 74 \\
\hline 4. Observation & 59 & 68 \\
\hline 5. Surveys & 59 & 68 \\
\hline 6. Prototyping & 54 & 62 \\
\hline 7. Scenarios & 50 & 57 \\
\hline 8. Focus group & 49 & 56 \\
\hline 9. JAD & 48 & 55 \\
\hline 10. Decision Trees & 47 & 54 \\
\hline 11. Use Cases & 44 & 51 \\
\hline 12. Role Playing & 38 & 44 \\
\hline 13. Quality Function Deployment (QFD) & 33 & 38 \\
\hline 14. Fault Tree Analysis & 23 & 26 \\
\hline 15. Flow Charts & 21 & 24 \\
\hline 16. Goal-Oriented Elicitation & 18 & 21 \\
\hline 17. Unified Modeling Language (UML) & 18 & 21 \\
\hline 18. Ishikawa & 5 & 06 \\
\hline 19. K.J. Method & 3 & 03 \\
\hline
\end{tabular}

Figure 2. show most used requirement elicitation techniques in Kuwait [21]

\subsubsection{Chinese characteristics of Requirement elicitation [22]}

A study into the using method of requirement elicitation in the Chinese market [20] listed that focus group is the highly liked used then prototype, document analysis and questionnaire. $78 \%$ of companies give more than $10 \%$ of their time to requirement and customers think it is very important. The culture is involved heavily in elicitation requirement as $96 \%$ of software companies say they must have a good relation with leader of customer companies. The leaders influence the level of cooperation of customer companies. As for the uncertainly avoided problems in China, people usually stay away from conflicts and uncertainties, and they tend to 
use gentle and indirect methods to deal with conflict. That is why when gathering requirement they tend to prefer prototype available to see the system. They are leaning toward collectivism more than individualism and issues environmental protection, energy saving, reduction of cost, security, safety receive good impact when added to projects. Software companies tend to interfere with customer requirement, $80 \%$ think customer doesn't know what he want and they are helping him. They are hardly using RE tools like DOORS only $14 \%$ which show that tools are not widely marketed.

This study shows that support from top management is vital into gathering requirement, collectivism is high as focus group is most used while an interview is lowly perceived and that understanding Chinese culture bring better requirement.

The limitation of this study there is no clear guidance on getting requirement form customers and requirement engineer tend to add lots of requirement.

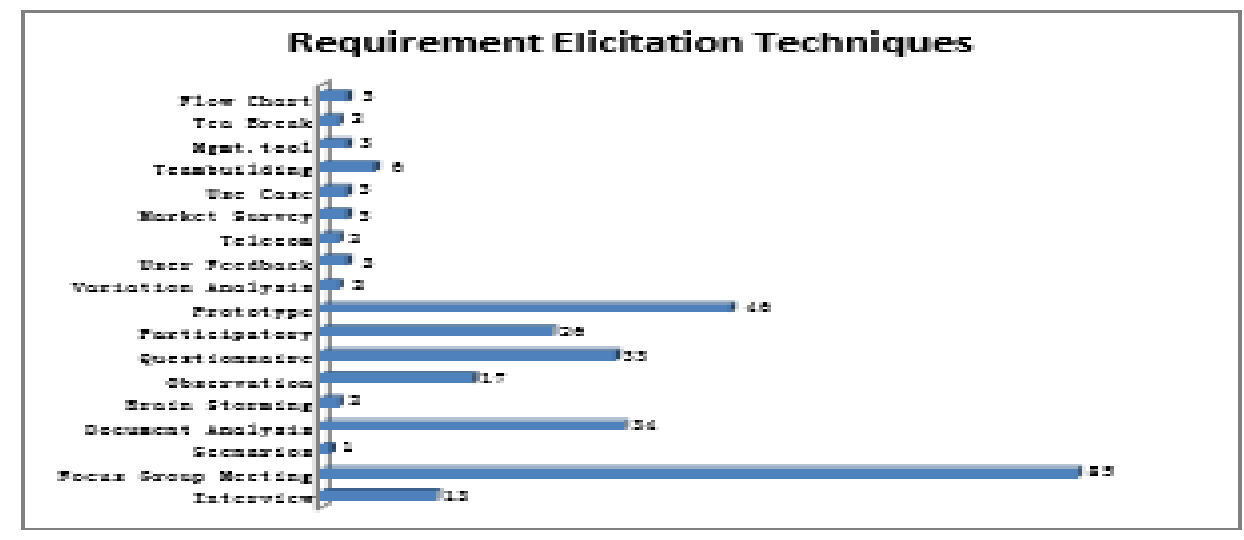

Figure 3. Show the most used requirement elicitation techniques in China [22]

\subsubsection{Requirement elicitation in Brazil}

A study comparing requirement elicitation in Brazil and Germany [23], show that both use interviews heavily $87 \%$ brazil and $88 \%$ Germany but there is a difference in meeting brazil $56 \%$ use workshop while Germany use it $86 \%$. The German companies will build product to customer using RE while Brazilian companies tend to build standard product then customize it to customer needs through RE. The main cause for problems and uncertainly requirements is different, in Brazil $40 \%$ people and the biggest factor in that is no expertise in RE see figure 4 then input itself $20 \%$ while in Germany methods $58 \%$ and organization 23\%. Brazilian companies use agile method which required extensive communication and collaboration between teams and when you consider the size of Brazil that is hugely challenging and can bring mistrust between the customer and requirement team.

This study shows that the lack of knowledge in the requirement team is the biggest problem in Brazil which is different from Germany (developed country) and that need to be addressed before gathering requirement. The limitation of this requirement, there in guide to deal with the culture effect in Brazil like lack of communication because of the size of the country. 
International Journal of Software Engineering \& Applications (IJSEA), Vol.8, No.1, January 2017

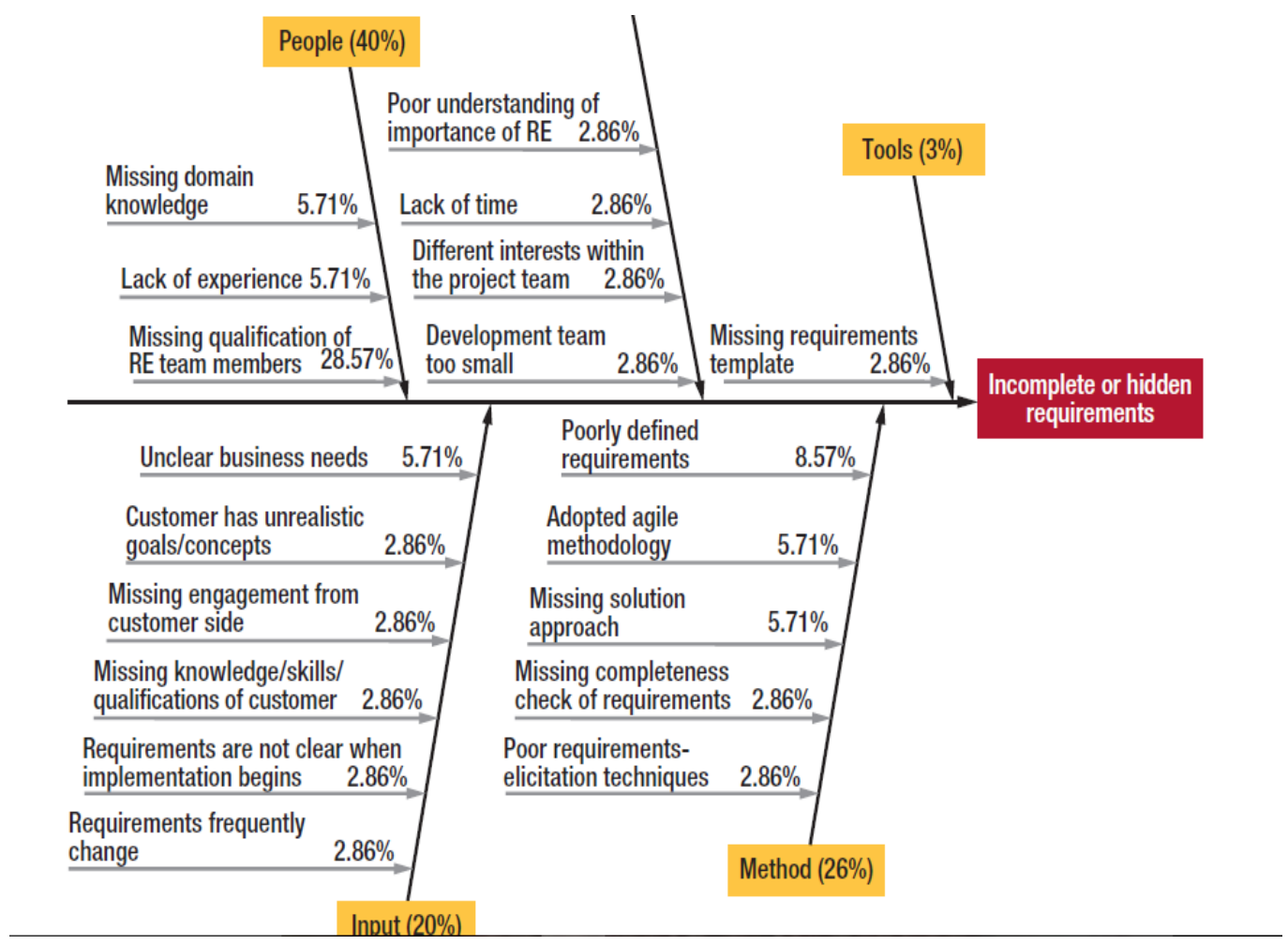

Figure 4. show the reasons for hidden and incomplete requirement in Brazil [23]

\subsubsection{In Africa rural areas}

When gathering requirement, there is a need to look at local needs [24], in most African countries there are special requirement has to be looked at, for example in Nigeria[25]. There is sustainability in developing country you have to look infrastructure and the environment to sustain project. Then affordability as information systems are still expensive to maintain. The social-economic is also a big factor. The study of requirement elicitation in Africa is very limited and given the size of the African cotenant and the complex of the social issues there, a lot more research need to be done in this area

\subsubsection{Requirement elicitation in India rural areas [27]}

Women in rural area in India similar to others in developing country are different to women in other places in term of culture, illiteracy and language variation. They depend on their local knowledge rather than global knowledge where IT is not much in use. They lack experience in giving requirement, struggle to fill government forms and not getting enough information to improve their living standard and enhance their children development. Similar to rural areas in Africa, images are well received instead of forms and questionnaires. Most communication is done through word of mouth and there are trusted people like doctors, teachers, elders and rich farmers. They go to most houses and can spread the word better than technology will ever do in this rural area. So you cannot use the general requirement elicitation techniques and has to design method suited to the local knowledge rather than international knowledge, matching the capabilities of women in rural areas. 
International Journal of Software Engineering \& Applications (IJSEA), Vol.8, No.1, January 2017

The paper has a right approach to get requirement in rural area in India and most of developing countries. Requirement engineers have to match the level of women in rural area to gain their trust to get their right needs and enhance the software usability. The study needs to be implemented to be able to value it and improve it .

\subsubsection{Requirement elicitation study in Thailand}

Thanasankit [29] explain in Thailand, culture change technology rather than technology change culture. Respect for the leader as a father figure is critical in Thai culture. The king of Thailand has passed away in 2016 after 70 years reign and was regard as father of the nation. Any questioning of the leadership in requirement engineering will lead into client becoming disengagement and would consider it as insult. A power in organization comes through person position in it rather than personality, influence or education. This is crucial to requirement elicitation process in Thailand. Also avoiding confrontation play an important role in Thai culture as avoiding conflicts and criticism is considered face saving value [30]. Thanasankit [29] argue that in Thailand, decision is usually taken at the top management and employees tend to stay away from it in order not to confront with top management. So any requirement that does not get the backing the top management are likely not to be done.

\subsubsection{Comparison between Requirement elicitation in Helsinki, Las Vegas and Hong Kong}

Tunnanen [13] argues than culture has a big effect on requirement. Understand the values and the culture of the society helps to better address its preference in building new IS systems. Tunnanen [13] has done requirement elicitation and analyzes to develop new mobile services involving 487 users from Helsinki, Las Vegas and Hong Kong. The study shows sharp differences in view between western cities (Helsinki and Las Vegas) and eastern city Hong Kong. Also there is a difference between the two western Cities. Tunnanen [13] used table 1 above with value typology. The study show residence of Hong Kong had high emphases toward personal values like comfortable live and exciting lives and so on, in comparison residence of Helsinki and Las Vegas put less emphasis on these values. Which goes with the United Nation publication of happiness index [27] which shows Finland $7^{\text {th }}$, Usa1 $7^{\text {th }}$ and Hong Kong $64^{\text {th }}$. On the instrumental values (see table 1) the moral and competency values were higher in Helsinki and Las Vegas than in Hong Kong which agrees with and Hostefede and hostefede [28] that Helsinki and Las Vegas are more individual than Hong Kong. Also Helsinki scored higher in moral and competency than Las Vegas. The Hong Kong user tends to associate themselves with tangible values than Helsinki and Las Vegas users. This study indicates that a culture friendly mobile IT system has more chances to success than in the 3 countries then one version of the system in the 3 countries.

\subsubsection{Requirement Elicitation in Sudan}

We interviewed two consultants from the leading IT companies in Sudan. The first company is using readymade products which will be adjusted to customer needs through agile method. This system rarely meets all the customer need and the agile method requires extensive communication which always becomes a problem.

The second company gather requirement from customer in one or two interview. This method is good but there is no guidance to the information coming from the customer like project, risks, deliverable, objectives, assumptions, opportunities, challenges, stakeholders, functional and nonfunctional requirement. They end up having to alter requirement several time during the projects which cost a lot of time and effort. 
International Journal of Software Engineering \& Applications (IJSEA), Vol.8, No.1, January 2017

In a comparison between Germany and Brazil (developing country) the difference is clear in reason to gen incomplete or hidden requirement [13]. In Brazil the problem with people $40 \%$ and input\%20. Problem with people because like in first company in Sudan above they develop product first with no interaction with customer then it is a problem to adjust to customer needs completely.

\subsubsection{Case Study (Bank ATM machine in Sudan)}

ATMs has been around in Sudan for the last ten years. They are located in most cities in Sudan. They are great help to get cash $24 / 7$ as everywhere else in Sudan. They were deployed with the same standard as the rest of the world without looking at special needs and culture effect in Sudan. As last review by the Unicef in 2015, the literacy level in Sudan is $70.2 \%$. when you consider Sudan population as 39 millions than means 11.7 millions Sudanese cannot read and write. As we all know to use a standard ATM you need to be able to read and write to put your pin and follow instruction. This is an huge obstacle for those $11.7 \mathrm{~m}$ and it is not unfamiliar to find an old man or woman at ATM asking for help in Sudan. The requirement analysis should have look at that and added voice recognition for example to make it accessible for everybody

\section{CONCLUSION}

Almost all the studies in developing world notice the unique social element in each country and how it effects the requirement elicitation. The aim of requirement engineer is to satisfy customer needs, to help guide the RE study the society with all the social aspect to be able to get the entire requirement on board. There is a gap between requirement elicitation in developed world and many areas in developing countries where mindset maybe different and prospect of method is different. There is still a lot of research need to be done in developing countries to find the ideal method for gathering requirement. Africa specially has the least bit of research done specifically in requirement elicitation [32].

\section{FURTHER WORK}

- The next stage is to have interpretation for what a culture means. Culture could be represented as constraints on models of requirements, then quires can be build to check satisfaction or violations.

- After deciding the characteristics of culture that is standard, and what level of abstraction that data will be gathered. Also the classification criteria to group them.

- A questionnaire will be prepared and handed in two countries, Sudan and Emirates to compare the culture in the African and Arab countries of the MENA. The result will be put into modeling using statistics methods like ANOVA AND ANCOVA

\section{REFERENCES}

[1] Lee, S.hyun. \& Kim Mi Na, (2008) “This is my paper”, ABC Transactions on ECE, Vol. 10, No. 5, pp120-122.

[2] Gizem, Aksahya \& Ayese, Ozcan (2009) Coomunications \& Networks, Network Books, ABC Publishers.

[3] Sadiq .M and Mohd .S (2009), Article in an International journal, "Elicitationand Prioritization of Software Requirements". Internation Journal of RecentTrends in Engineering, Vol.2, No.3, pp. 138142.

[4] Bergey, John, et al. Why Reengineering Projects Fail. No. CMU/SEI-99-TR-010. CARNEGIEMELLON UNIV PITTSBURGH PA SOFTWARE ENGINEERING INST, 1999. 
International Journal of Software Engineering \& Applications (IJSEA), Vol.8, No.1, January 2017

[5] Goguen, J. A., Linde, C. (1993): Techniques for Requirements Elicitation, International Symposium on Requirements Engineering, pp. 152-164, January 4-6, San Diego, CA.

[6] Robertson, S., Robertson, J. (1999) Mastering the Requirements Process, Addison Wesley: Great Britain.

[7] Iqbal, Tabbassum, and Mohammad Suaib. "Requirement Elicitation Technique:-A Review Paper." Int. J. Comput. Math. Sci 3.9 (2014).

[8] HOFSTEDE G (1980) Culture's Consequences: International Differences in Work-Related Values. Sage, Newbury Park, CA.

[9] SCHEIN EH (1985) Organisational Culture and Leadership. Jossey-Bass, San Francisco, CA.

[10] LYTLE AL, BRETT JM, BARSNESS ZI, TINSLEY CH and JANSSENS M (1999) A paradigm for confirmatory cross-cultural research in organizational behavior. Research in Organizational Behavior 17, 167-214, https:// lirias.kuleuven.be/handle/123456789/31199.

[11] Kluckhohn, K (1954) Culture and behavior. In G. Lindsey (ED.) handbook of social psychology

[12] TRIANDIS HC (1995) Individualism \& Collectivism. Westview Press, Boulder, CO.

[13] ROKEACH M (1973) The Nature of Human Values. Free Press, New York.

[14] KARAHANNA E, EVARISTO JR and SRITE M (2005) Levels of culture and individual behavior: an integrative perspective. Journal of Global Information Management 13(2), 1-20

[15] Fernández, Daniel Méndez, and Stefan Wagner. "Naming the pain in requirements engineering: A design for a global family of surveys and first results from Germany." Information and Software Technology 57 (2015): 616-643.

[16] Davis, Gordon B. "Strategies for information requirements determination."IBM systems journal 21.1 (1982): 4-30.

[17] Rouibah, Kamel. "Social usage of instant messaging by individuals outside the workplace in Kuwait: A structural equation model." Information Technology \& People 21.1 (2008): 34-68.

[18] Byrd, Terry Anthony, Kathy L. Cossick, and Robert W. Zmud. "A synthesis of research on requirements analysis and knowledge acquisition techniques."MIS quarterly (1992): 117-138.

[19] Arnott, David, Waraporn Jirachiefpattana, and Peter O'Donnell. "Executive information systems development in an emerging economy." Decision Support Systems 42.4 (2007): 2078-2084.

[20] Kontio, Jyrki, Laura Lehtola, and Johanna Bragge. "Using the focus group method in software engineering: obtaining practitioner and user experiences."Empirical Software Engineering, 2004. ISESE'04. Proceedings. 2004 International Symposium on. IEEE, 2004.

[21] Agarwal, Ritu, Atish P. Sinha, and Mohan Tanniru. "The role of prior experience and task characteristics in object-oriented modeling: an empirical study." International journal of humancomputer studies 45.6 (1996): 639-667.

[22] Liu, Lin, et al. "Understanding chinese characteristics of requirements engineering." 2009 17th IEEE International Requirements Engineering Conference. IEEE, 2009.

[23] Rouibah, Kamel, and Sulaiman Al-Rafee. "Requirement engineering elicitation methods: A Kuwaiti empirical study about familiarity, usage and perceived value." Information management \& computer security 17.3 (2009): 192-217.

[24] Liu, Lin, et al. "Understanding chinese characteristics of requirements engineering." 2009 17th IEEE International Requirements Engineering Conference. IEEE, 2009.

[25] Fernández, Daniel Méndez, and Stefan Wagner. "Naming the pain in requirements engineering: A design for a global family of surveys and first results from Germany." Information and Software Technology 57 (2015): 616-643.

[26] Winschiers-Theophilus, Heike, et al. "Determining requirements within an indigenous knowledge system of African rural communities." Proceedings of the 2010 Annual Research Conference of the South African Institute of Computer Scientists and Information Technologists. ACM, 2010.

[27] Mursu, Anja, et al. "Information systems development in a developing country: Theoretical analysis of special requirements in Nigeria and Africa."System Sciences, 2000. Proceedings of the 33rd Annual Hawaii International Conference on. IEEE, 2000.

[28] Anwar, Fares, and Rozilawati Razali. "A practical guide to requirements elicitation techniques selection-An empirical study." Middle-East Journal of Scientific Research 11.8 (2012): 1059-1067.

[29] HELLIWELL J, LAYARD R and SACHS J (2013) World happiness report 2013, United Nations.

[30] HOFSTEDE G andHOFSTEDE GJ (2005) Cultures and Organisations: Software of the Mind. McGraw-Hill, New York.

[31] Thanasankit, Theerasak, and Brian Corbitt. "Cultural context and its impact on requirements elicitation in Thailand." EJISDC: The Electronic Journal on Information Systems in Developing Countries 1 (2000): 2. 
International Journal of Software Engineering \& Applications (IJSEA), Vol.8, No.1, January 2017

[32] Komin, S. (1990). Psychology of the Thai People: Values and Behavioral Patterns. Bangkok, Thailand: NIDA (National Institute of Development Administration).

[33] Khan ${ }^{1}$, Shadab, Aruna B. Dulloo, and Meghna Verma. "Systematic review of requirement elicitation techniques." (2014).

[34] Sadig, Ayman. "Requirements Engineering Practice in Developing Countries: Elicitation and Traceability Processes." Proceedings of the International Conference on Software Engineering Research and Practice (SERP). The Steering Committee of The World Congress in Computer Science, Computer Engineering and Applied Computing (WorldComp), 2016.

[35] Wiegers, Karl, and Joy Beatty. Software requirements. Pearson Education, 2013

\section{Authors}

Ayman Sadig, MSc for advance software engineering from westminister University in UK, doing PHD at present at Sudan University in Sudan, Publisher of paper "Requirements Engineering Practice in Developing Countries Elicitation and Traceability Processes"

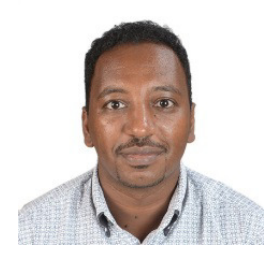

Abd-El-Kader Sahraoui , Professor in systems engineering at Toulouse University at LAAS-CNRS France. 